Rev. Bras. Saúde Prod. Anim., Salvador, v.16, n.1, p.1-9 jan./mar., 2015 http://www.rbspa.ufba.br

\title{
Análise econômica da inclusão de farinha do resíduo de tucumã (Astrocaryum vulgare, Mart) na alimentação de poedeiras comerciais
}

\author{
Economical analysis of the inclusion of flour residue of tucumã ("Astrocaryum \\ vulgare", Mart) in the feeding of laying hens
}

\section{RUFINO, João Paulo Ferreira ${ }^{1}$; CRUZ, Frank George. Guimarães ${ }^{1 *}$; MILLER, Waldo Plácido Mateus ${ }^{2}$; MELO, Ramon Duque ${ }^{1}$; FEIJÓ, Julmar da Costa ${ }^{1}$; CHAGAS, Ewerton Oliveira das ${ }^{3}$}

\author{
${ }^{1}$ Universidade Federal do Amazonas, Faculdade de Ciências Agrárias, Setor de Avicultura, Manaus, \\ Amazonas, Brasil. \\ ${ }^{2}$ Zootecnista, Autônomo, Manaus, Amazonas, Brasil. \\ ${ }^{3}$ Universidade Federal Rural da Amazônia, Manaus, Programa de Pós-Graduação em Biotecnologia \\ Aplicada à Agropecuária, Manaus, Amazonas, Brasil. \\ *Endereço para correspondência: frankgcruz@gmail.com
}

\section{RESUMO}

Objetivo-se com este trabalho analisar economicamente a inclusão de níveis de farinha do resíduo de tucumã (Astrocaryum vulgare, Mart), $(0 ; 5 ; 10 ; 15$ e $20 \%)$ em rações para poedeiras comerciais leves. $\mathrm{O}$ experimento teve duração de 84 dias divididos em quatro períodos de 21 dias, sendo utilizadas 160 poedeiras Dekalb White com 56 semanas. A farinha resíduo de tucumã foi utilizada nas rações como fonte energética e pigmentante da gema do ovo. O delineamento experimental foi inteiramente casualizado com cinco tratamentos e quatro repetições de oito aves cada e os dados foram analisados utilizando regressão polinomial. O consumo acumulado de ração apresentou diferenças significativas $(\mathrm{P}<0,05)$ sendo o nível de $6,27 \%$ o que apresentou maior consumo acumulado e o nível de $4,67 \%$ o ponto ótimo econômico para o consumo, havendo uma redução de até $\mathrm{R} \$ 31,26$ no custo de produção das rações considerando o nível de maior inclusão e o nível sem inclusão. $\mathrm{O}$ custo alimentar apresentou diferenças significativas $(\mathrm{P}<0,05)$, onde foi observado decréscimo no mesmo a partir da inclusão de farinha do resíduo de tucumã. Não foram encontradas diferenças significativas $(\mathrm{P}>0,05)$ para as demais variáveis. A farinha do resíduo de tucumã pode ser utilizada como ingrediente alternativo nas rações de poedeiras comerciais leves tendo o nível de inclusão de 5\% apresentado maior rentabilidade. Até $20 \%$ de inclusão o custo das rações foi menor e o valor agregado bruto maior.

Palavras-chave: alimento alternativo, consumo de ração, custo, rentabilidade

\section{SUMMARY}

The objective of this study were analyzed economically the inclusion of different levels of flour residue of tucumã (Astrocaryum vulgare, Mart) $(0,5,10,15$ and 20\%) in diets for laying hens. The experiment lasted 84 days divided into four periods of 21 days, where were used 160 birds Dekalb White with 56 weeks of age. The residue tucumã flour was used in diets as an energy source and colored egg yolk. The experimental design was completely randomized with five treatments and four replicates of eight birds each, and data were analyzed using polynomial regression. The cumulative feed intake showed significant differences $(\mathrm{P}<0.05)$ with the level of $6.27 \%$ had the highest cumulative consumption in level of $4.67 \%$ and the economic optimum point for consumption, with a reduction of up to $\mathrm{R} \$$ 31.268 in the production cost of rations considering the level of inclusion and higher level without inclusion. The feed cost of the feed showed significant differences $(\mathrm{P}<0.05)$ decrease in cost checking as increased the level of inclusion as $5 \%$. No were found significant differences $(\mathrm{P}>0.05)$ for the other variables. The residue flour of tucumã can be used as an alternative ingredient in diets for laying hens with the inclusion level of $5 \%$ showed higher profitability. Up to $20 \%$, the cost of feed was lower and higher profits.

Keywords: alternative food, costs, feed intake, profitability 


\section{INTRODUÇÃO}

A Amazônia possui inúmeras espécies nativas de plantas frutíferas que apresentam potencial econômico, tecnológico e nutricional, que vêm despertando o interesse de estudos científicos em diversas áreas, tais como: alimentícia, farmacêutica, cosmética, aromatizante e essências (CLEMENT et al., 2005). O tucumã destaca-se entre estas, devido principalmente às suas diversas propriedades nutricionais, como fonte de caloria, fibras, próvitamina A (caroteno) e lipídeos, especialmente do ácido graxo oleico sendo de grande valia para a agroindústria (FERREIRA et al., 2008) e gerador de resíduos orgânicos com potencial biológico para o reaproveitamento. Até o presente momento, a única referencia quanto à utilização de farinha do resíduo de tucumã em rações para aves é o relato de Miller et al. (2013) que avaliaram o desempenho zootécnico da farinha do resíduo de tucumã em rações para poedeiras comerciais leves e afirmam que estas características encontradas no tucumã potencializam a utilização deste nas rações, representando assim sua viabilidade produtiva.

No contexto encontrado principalmente no Estado do Amazonas, com restrição de recursos e alto valor de matérias primas, as pesquisas com alimentos alternativos em rações para aves visam principalmente minimizar os custos com alimentação, tendo em vista que estes correspondem à cerca $80 \%$ dos custos totais de produção. E, em pesquisas com ingredientes alternativos para aves, a análise econômica dos resultados experimentais é muito importante, uma vez que produtores e especialistas disporão de critérios que irão contribuir para utilização dos mesmos de forma mais cautelosa (SILVA et al., 2009).
As análises econômicas, associadas às análises produtivas, podem fornecer informações acerca de um determinado alimento alternativo e como este pode acrescentar ao sistema de produção, sendo a utilização de resíduos da agroindústria, como o resíduo de tucumã, opções interessantes tanto do ponto de vista produtivo quanto ambiental (LOUREIRO et al., 2007). Desta forma, o trabalho teve como objetivo analisar economicamente a inclusão de farinha do resíduo de tucumã em rações para poedeiras comerciais leves.

\section{MATERIAL E MÉTODOS}

O experimento foi conduzido no Setor de Avicultura do Departamento de Produção Animal e Vegetal - DPAV da Faculdade de Ciências Agrárias - FCA da Universidade Federal do Amazonas UFAM, localizado no Setor Sul do Campus Universitário, Manaus/AM, durante 84 dias entre os meses de março e maio de 2011, divididos em quatro ciclos de 21 dias cada. Foram utilizadas 160 aves da linhagem Dekalb White com 56 semanas de idade alojadas em gaiolas de arame galvanizado medindo $1,00 \times 0,40 \times 0,45 \mathrm{~cm}$.

As aves foram distribuídas em um delineamento inteiramente casualizado com cinco níveis de inclusão de farinha do resíduo de tucumã $(0 ; 5 ; 10 ; 15$ e $20 \%$ ) nos tratamentos e quatro repetições de 8 aves cada. Foi adotado um período de adaptação às rações experimentais e às instalações de 15 dias antes do inicio do experimento.

$\mathrm{O}$ resíduo de tucumã (oriundo da retirada da polpa do fruto) utilizado para obtenção da farinha processada foi coletado nas feiras e mercados existentes na cidade de Manaus/AM. Após a coleta, o resíduo foi submetido à um processo de seleção, rejeitando-se 
Rev. Bras. Saúde Prod. Anim., Salvador, v.16, n.1, p.1-9 jan./mar., 2015 http://www.rbspa.ufba.br

qualquer material em decomposição e que pudesse levar prejuízo nutricional e sanitário às aves. Em seguida, o resíduo selecionado foi lavado, submetido à secagem ao ar durante quatro dias $\mathrm{e}$ posteriormente triturado obtendo assim o produto denominado farinha do resíduo de tucumã (FRT), sendo em seguida este ensacado e armazenado em local seco e ventilado para posterior utilização nas rações.

Posteriormente ao preparo, foram coletadas amostras do produto e enviadas ao Laboratório de Aquicultura do Instituto Nacional de Pesquisas da Amazônia - INPA para determinação da composição centesimal, sendo os resultados demonstrados na Tabela 1.

Tabela 1. Composição centesimal da farinha do resíduo de tucumã (F.R.T.). ${ }^{1}$

\begin{tabular}{lc}
\hline Componentes & Composição \\
\hline Matéria seca (\%) & 89,78 \\
Proteína bruta, \% & 9,33 \\
Fibra bruta, \% & 14,63 \\
Fibra detergente neutra, \% & 53,98 \\
Fibra detergente ácida, \% & 38,63 \\
Gordura, \% & 12,66 \\
Matéria mineral, \% & 4,49 \\
$\begin{array}{l}\text { Energia metabolizável }{ }^{2}, \\
\text { kcal/kg-1 }\end{array}$ & 3.267 \\
${ }^{1}$ Fonte: Miller et al. (2013). & \\
${ }^{2}$ Foi determinada através de ensaio de \\
$\begin{array}{l}\text { metabolismo utilizando poedeiras } \\
\text { onde obteve-se o valor em kcal kg }{ }^{-1} \text {. }\end{array}$
\end{tabular}

As rações experimentais foram formuladas utilizando o software computacional Supercrac (2004) segundo as recomendações do manual da linhagem (GRANJA PLANALTO, 2009) e conforme os valores dos ingredientes fornecidos pelas Tabelas Brasileiras para Aves e Suínos (ROSTAGNO et al., 2011), com exceção da composição da farinha de resíduo de tucumã (FRT) e encontramse na Tabela 2.

A água e as rações foram fornecidas at libitum às aves em bebedouros do tipo nipple e comedouros do tipo calha, respectivamente. Durante todo o período experimental foram fornecidas 16 horas de luz/dia (natural+artificial) com fornecimento de luz artificial nos horários de 20:00 à 22:00 hs e 04:00 à 06:00 hs, respectivamente. Todas as aves foram pesadas no início do experimento para uniformização das parcelas a apresentaram peso médio de $1,53 \pm 0,063 \mathrm{~kg}$. A coleta de ovos foi realizada três vezes ao dia (às $8 ; 11$ e 16 hs) sendo registrada cada ocorrência (quantidade de ovos de cada coleta, mortalidade ocasional dentre outras). Ao final de cada ciclo as folhas de controle de produção foram recolhidas para determinação da produção de ovos, a partir do total produzido comercializável por cada parcela, e a sobra de ração dos comedouros foi pesada para determinação do consumo acumulado de ração de cada período.

As variáveis analisadas foram: consumo de ração acumulado (kg), custo alimentar (R\$), produção de ovos, custo de produção dos ovos (R\$), receita bruta $(\mathrm{R} \$)$, valor agregado bruto $(\mathrm{R} \$)$, índice de rentabilidade (\%) e ponto de equilíbrio.

Para determinação do preço da ração e dos custos de produção foram utilizados apenas os valores por quilo das matérias-primas utilizadas e o preço atualizado destas na região no período de realização do experimento, que foram: milho, $\mathrm{R} \$ 0,30$; farelo de soja, $\mathrm{R} \$ 1,20$; calcário, $\mathrm{R} \$ 0,41$; sal comum, $\mathrm{R} \$ 0,40$; fosfato bicálcico, R\$ 1,92; DLMetionina, R\$ 12,50; L-Lisina HCL, R\$ 10,8; e suplemento mineral e vitamínico, R\$ 9,98. Para o cálculo do custo da farinha do resíduo de tucumã levou- 
Rev. Bras. Saúde Prod. Anim., Salvador, v.16, n.1, p.1-9 jan./mar., 2015 http://www.rbspa.ufba.br ISSN 15199940

se em consideração apenas as despesas com transporte e manejo do produto, e estimou-se o preço em quilo do produto em $\mathrm{R} \$$ 0,30. Os custos fixos não se alteraram durante o período experimental, sendo considerados constantes para todos os tratamentos.

Tabela 2. Composição das rações contendo farinha de resíduo de tucumã (F.R.T.) ${ }^{2}$

\begin{tabular}{|c|c|c|c|c|c|}
\hline \multirow{2}{*}{ Ingredientes } & \multicolumn{5}{|c|}{ Níveis de Farinha do Resíduo de Tucumã (\%) } \\
\hline & 0 & 5 & 10 & 15 & 20 \\
\hline Milho & 64,29 & 59,63 & 54,96 & 50,29 & 45,61 \\
\hline F. soja $(46 \%)$ & 24,09 & 23,76 & 23,37 & 22,99 & 22,60 \\
\hline Far. Res. Tucumã & 0,00 & 5,00 & 10,00 & 15,00 & 20,00 \\
\hline Calcário calcítico & 8,97 & 8,85 & 8,76 & 8,67 & 8,58 \\
\hline Fosfato bicálcico & 1,72 & 1,75 & 1,78 & 1,8 & 1,83 \\
\hline Premix vit. min. ${ }^{1}$ & 0,50 & 0,50 & 0,50 & 0,50 & 0,50 \\
\hline DL- Metionina (99\%) & 0,08 & 0,08 & 0,10 & 0,13 & 0,15 \\
\hline L-Lisina HCL $(78,4 \%)$ & 0,00 & 0,08 & 0,18 & 0,27 & 0,38 \\
\hline Sal & 0,35 & 0,35 & 0,35 & 0,35 & 0,35 \\
\hline Total & 100,00 & 100,00 & 100,00 & 100,00 & 100,00 \\
\hline \multicolumn{6}{|l|}{ Nutriente } \\
\hline E.M, $\mathrm{kcal}^{-1} / \mathrm{kg}$ & 2.750 & 2.750 & 2.750 & 2.750 & 2.750 \\
\hline Proteína bruta, \% & 16,50 & 16,50 & 16,50 & 16,50 & 16,50 \\
\hline Metionina + Cistina, $\%$ & 0,62 & 0,61 & 0,61 & 0,61 & 0,61 \\
\hline Metionina, $\%$ & 0,34 & 0,34 & 0,35 & 0,36 & 0,37 \\
\hline Lisina, $\%$ & 0,84 & 0,90 & 0,98 & 1,06 & 1,13 \\
\hline Cálcio, \% & 4,00 & 4,00 & 4,00 & 4,00 & 4,00 \\
\hline Fibra Bruta, $\%$ & 2,71 & 3,33 & 3,96 & 4,58 & 5,20 \\
\hline Gordura, $\%$ & 2,29 & 2,77 & 3,25 & 3,73 & 4,20 \\
\hline Fósforo Disponível, \% & 0,37 & 0,37 & 0,37 & 0,37 & 0,37 \\
\hline Sódio, \% & 0,18 & 0,17 & 0,17 & 0,17 & 0,17 \\
\hline
\end{tabular}

${ }^{1}$ Níveis de garantia por quilograma de produto: Vitamina A 2.000.000 UI, Vitamina D3 400.000 UI, Vitamina E $2.400 \mathrm{mg}$, Vitamina K3 $400 \mathrm{mg}$, Vitamina B1 $100 \mathrm{mg}$, Vitamina B2 $760 \mathrm{mg}$, Vitamina B6 $100 \mathrm{mg}$, Vitamina B12 $2.400 \mathrm{mcg}$, Niacina $5.000 \mathrm{mg}$, Pantotenato de Cálcio $2000 \mathrm{mg}$, Ácido Fólico 50 $\mathrm{mg}$, Cocciostático $12.000 \mathrm{mg}$, Colina $50.000 \mathrm{mg}$, Cobre $1.200 \mathrm{mg}$, Ferro $6.000 \mathrm{mg}$, Manganês 14.000 $\mathrm{mg}$, Zinco $10.000 \mathrm{mg}$, Iodo $100 \mathrm{mg}$. Selênio $40 \mathrm{mg}$. Veículo Q.S.P. $1.000 \mathrm{~g}$.

${ }^{2}$ Fonte: Miller et al. (2013).

O custo alimentar (CA), único custo de produção utilizado como variável, foi determinado através da aquisição dos ingredientes e confecção da ração, sendo estimado pela fórmula: $\mathrm{CA}=$ CRA $\mathrm{x}$ PR, onde $\mathrm{CA}=$ custo com alimentação (R\$), CRA = consumo de ração acumulado $(\mathrm{kg})$ e $\mathrm{PR}=$ preço do quilo de ração $(\mathrm{R} \$ / \mathrm{kg})$. O custo de produção por ovos foi obtido do quociente do total de ovos produzidos pelo custo total de produção dos ovos, neste caso o custo alimentar, pela fórmula, $\mathrm{CPO}=\mathrm{Q} / \mathrm{CA}$, onde $\mathrm{CP}=$ custo de produção por ovo, $\mathrm{Q}=$ quantidade de ovos produzidos, e $\mathrm{CA}=$ custo alimentar (ROSSETI, 1990).

A receita bruta foi obtida a partir do cálculo de acordo com a produção de ovos e o preço de venda por unidade do produto, em que $\mathrm{RB}=\mathrm{Q} \times \mathrm{PV}$, onde $\mathrm{RB}$ $=$ receita bruta $(\mathrm{R} \$), \mathrm{Q}-$ quantidade de ovos produzidos por unidade, e $\mathrm{PV}=$ preço de venda de cada ovo (ROSSETI, 2004). Para o preço de venda dos ovos por unidade, aplicado no cálculo de margem bruta de valor agregado bruto, foi utilizado o preço praticado na região à época da realização do experimento 
Rev. Bras. Saúde Prod. Anim., Salvador, v.16, n.1, p.1-9 jan./mar., 2015 http://www.rbspa.ufba.br

sendo assim este valor fixado em R\$ 0,24/unidade.

$\mathrm{O}$ valor agregado bruto (VAB) foi calculado a partir da diferença entre o total acumulado da venda dos ovos e o custo com alimentação, de acordo com a seguinte fórmula: $\mathrm{LO}=\mathrm{RB}-\mathrm{CA}$ em que $\mathrm{VAB}=$ valor agregado bruto $(\mathrm{R} \$)$, $\mathrm{CA}=$ custo com alimentação ( $\mathrm{R} \$)$ e $\mathrm{RB}$ $=$ receita bruta $(\mathrm{R} \$)$. O índice de rentabilidade indica a taxa disponível de receita. Para o cálculo deste índice considerou-se a fórmula: $\mathrm{IL}=(\mathrm{LO} / \mathrm{RB})$ x 100 (ROSSETI, 1990).

$\mathrm{O}$ ponto de equilíbrio define a quantidade de ovos necessários para cobrir os custos com alimentação no presente trabalho. Sendo assim, considerando que a RB é produto entre a Quantidade de ovo produzido por unidade (Q) e o preço de venda cada ovo (PV), e o Custo de Produção (CP) é produto entre a quantidade de ração consumida e o preço da ração conforme tratamento utilizado tem-se: $\mathrm{RB}=\mathrm{Q} \mathrm{x}$ $\mathrm{PV}$ e, $\mathrm{CP}=\mathrm{CRA} \times \mathrm{PR}$. Logo, o ponto de equilíbrio se estabelece quando: $\mathrm{RB}$
$=\mathrm{CP}$, receita bruta é igual ao custo de produção, ou, $\mathrm{Q} \times \mathrm{PV}=\mathrm{CRA} \times \mathrm{PR}$ (ROSSETI, 2004).

Os dados coletados foram submetidos a análise variância utilizando o procedimento GLM do programa computacional Statistical Analysis System SAS (STATISTICAL ANALYSIS SYSTEMS, 2008) e as estimativas dos tratamentos foram submetidas à análise de regressão polinomial aos níveis de 0,01 e 0,05 de probabilidade. Os modelos para determinação do comportamento das variáveis teve como base a significância de cada parâmetro da equação, o valor do coeficiente de determinação e a consonância do nível estimado.

\section{RESULTADOS E DISCUSSÃO}

Os resultados referentes à análise econômica do custo da ração contendo farinha do resíduo de tucumã (F.R.T.) relacionada com a produção de ovos estão expostos na Tabela 3.

Tabela 3. Preço da ração (PR), consumo de ração (CR), custo alimentar (CA), produção de ovos (PO) e custo de produção de ovos (CPO) para poedeiras leves alimentadas com rações contendo diferentes níveis de inclusão de farinha do resíduo de tucumã (F.R.T.)

\begin{tabular}{lccccccc}
\hline \multirow{2}{*}{ Variáveis } & \multicolumn{2}{c}{ Níveis de inclusão de farinha do resíduo de tucumã (\%) } & $\mathrm{R}^{2}$ & $\begin{array}{c}\text { CV } \\
(\%)\end{array}$ \\
\cline { 2 - 7 } & 0 & 5 & 10 & 15 & 20 & \\
\hline Preço da ração, $\mathrm{R} \$ / \mathrm{kg}$ & 0,876 & 0,863 & 0,854 & 0,845 & 0,836 & - & - \\
Consumo de ração, $\mathrm{kg} *$ & $85,60^{\mathrm{b}}$ & $84,27^{\mathrm{ab}}$ & $82,55^{\mathrm{ab}}$ & $79,20^{\mathrm{ab}}$ & $77,92^{\mathrm{a}}$ & 0,53 & 3,73 \\
Custo alimentar, $\mathrm{R}$ \$ $^{*}$ & $74,98^{\mathrm{b}}$ & $72,72^{\mathrm{b}}$ & $70,50^{\mathrm{ab}}$ & $66,93^{\mathrm{a}}$ & $65,14^{\mathrm{a}}$ & 0,68 & 3,71 \\
Produção de ovos, uni & 408,75 & 404,25 & 407,25 & 402,75 & 394,75 & - & 6,51 \\
Custo de produção, $\mathrm{R} \$$ /uni & 0,18 & 0,18 & 0,17 & 0,16 & 0,16 & - & 6,72 \\
\hline
\end{tabular}

*Efeito quadrático $(\mathrm{P}<0,05)$.

$\mathrm{CV}=$ coeficiente de variação; $\mathrm{R}^{2}=$ coeficiente de determinação.

O consumo acumulado de ração durante o período apresentou diferenças significativas $(\mathrm{P}<0,05)$, sendo possível através da derivação da função de produção $\left(\mathrm{Y}=-11 \mathrm{x}^{2}-1,38 \mathrm{x}+87,26\right.$, $\left.\mathrm{R}^{2}=0,53\right)$ obter o ponto de máximo consumo acumulado de ração (91,58 $\mathrm{kg}$ ) no nível de $6,27 \%$ de inclusão de 
farinha do resíduo de tucumã. Fixandose o preço da ração em $\mathrm{R} \$ 0,86$ (a partir do preço obtido do máximo consumo) estimou-se o ponto ótimo econômico para o consumo de ração nesta faixa de preço no nível de $4,67 \%$ de inclusão de farinha do resíduo de tucumã por quilo de ração que representou uma redução de até $\mathrm{R} \$ 10,85$ no custo de produção da ração em relação ao ponto máximo de produção. Economicamente, a partir da inclusão dos níveis de farinha do resíduo de tucumã em até $20 \%$ na ração, houve redução de $\mathrm{R} \$ 0,40$ por quilo no preço da ração, representando assim uma economia de até R $\$ 31,16$ no custo de produção da ração levando em consideração a diferença entre $o$ consumo da ração referência e da ração com $20 \%$ de inclusão de farinha do resíduo de tucumã.

$\mathrm{O}$ custo alimentar apresentou diferenças significativas $\quad(\mathrm{P}<0,05), \quad$ onde foi observado decréscimo no mesmo a partir da inclusão de farinha do resíduo de tucumã., sendo que o único custo a ser considerado foi o custo com alimentação. A partir da equação do custo alimentar $\left(\mathrm{Y}=-0,028 \mathrm{x}^{2}-2,37 \mathrm{x}+\right.$ $\left.77,50, \mathrm{R}^{2}=0,68\right)$ verificou-se o ponto de máximo custo alimentar na ração sem inclusão de F.R.T. A utilização de resíduos agropecuários nas rações pode, naturalmente, levar à redução no custo de produção por serem substitutos de commodities como o milho, por exemplo.

Por outro lado, nem sempre a substituição determina um melhor resultado econômico, conforme afirmam Costa et al. (2009) que em seus resultados indicaram que fatores como facilidade de aquisição, produção e flutuação dos preços dos insumos devem ser considerados na decisão pela utilização ou não de um ingrediente alternativo, e estes comprovam a viabilidade econômica de utilização deste determinado produto.

Ao associar os resultados obtidos em análises econômicas com os resultados zootécnicos utilizando produtos de origem vegetal na dieta das aves, como é o caso da farinha do resíduo de tucumã, deve-se considerar limitações biológicas oriundas da presença de fatores anti-nutricionais nos supracitados que podem ocasionar diminuição da digestibilidade dos nutrientes ingeridos, afetando $\mathrm{o}$ desempenho animal (OLIVEIRA et al., 2000) e consequentemente afetando os resultados econômicos, podendo ocasionar potenciais reduções no consumo, na produção e, principalmente, nos índices de rentabilidade.

Não foram encontradas diferenças significativas $(\mathrm{P}>0,05)$ para produção de ovos e custo para produção dos ovos. Porém, observou-se redução de até R\$ 10,41 no custo de produção dos ovos a partir da inclusão de farinha do resíduo de tucumã na ração $(5 ; 10 ; 15$ e $20 \%)$, que pode ser decorrente, todavia, da redução do consumo acumulado de ração que afetou negativamente a produção de ovos. Estes resultados corroboram com a afirmativa Franzoi et al. (1998) que refletem a importância de estudar fontes alternativas e alimentos não convencionais visando reduzir $o$ custo das rações, mas mantendo o bom desempenho dos animais.

Os resultados referentes à análise de receita e valor agregado bruto estão expostos na Tabela 4. Estatisticamente, não foram encontradas diferenças significativas $(\mathrm{P}>0,05)$ na receita bruta, valor agregado bruto, índice de rentabilidade e ponto de equilíbrio.

Observa-se, economicamente, uma relação inversamente proporcional entre a receita bruta, o valor agregado bruto e os índices de rentabilidade, pois, à medida que aumenta-se o nível de 
Rev. Bras. Saúde Prod. Anim., Salvador, v.16, n.1, p.1-9 jan./mar., 2015 http://www.rbspa.ufba.br ISSN 15199940

inclusão de farinha do resíduo de tucumã nas rações, nota-se queda na receita bruta acumulada, em contrapartida, aumenta-se o valor agregado bruto, consequentemente afetando o índice de rentabilidade.

A decorrente utilização de farinha do resíduo de tucumã nas rações, pelo baixo custo apresentado, possui potencial para diminuir a dependência do produtor na aquisição de insumos em regiões com baixa disponibilidade destes, principalmente do milho em regiões de difícil acesso, assim como outros alimentos alternativos com potencial já comprovado (SANTOS \& GRANJEIRO, 2012). Esta constatação reflete a importância de estudos de alimentos não convencionais capazes de promover a redução de custos das rações sem perdas substanciais para o desempenho dos animais (CRUZ et al., 2006), principalmente, pensando no sistema agrícola familiar que possui maior restrição orçamentária em relação aos demais.

Tabela 4. Receita bruta (RB), valor agregado bruto (VAB), índice de rentabilidade (IR) e ponto de equilíbrio (PE) obtidos para poedeiras leves alimentadas com rações contendo diferentes níveis de inclusão de farinha do resíduo de tucumã (F.R.T.)

\begin{tabular}{|c|c|c|c|c|c|c|c|}
\hline \multirow{2}{*}{ Variáveis } & \multicolumn{5}{|c|}{ Níveis de inclusão de farinha do resíduo de tucumã (\%) } & \multirow[t]{2}{*}{$\mathrm{R}^{2}$} & \multirow[t]{2}{*}{$\begin{array}{l}\text { CV } \\
(\%) \\
\end{array}$} \\
\hline & 0 & 5 & 10 & 15 & 20 & & \\
\hline Receita bruta, R\$ & 98,10 & 97,02 & 97,74 & 96,66 & 94,74 & - & 6,51 \\
\hline Valor agregado bruto, $\mathrm{R} \$$ & 23,11 & 24,29 & 27,23 & 29,72 & 29,59 & - & 17,42 \\
\hline Índice de Rentabilidade, $\%$ & 23,32 & 24,91 & 27,82 & 30,51 & 30,87 & - & 17,72 \\
\hline Ponto de equilíbrio & 0,48 & 0,48 & 0,48 & 0,47 & 0,46 & - & 6,51 \\
\hline
\end{tabular}

Porém, antes de se realizar quaisquer analises de rentabilidade de um alimento alternativo nas rações, deve-se considerar a relação existe entre o valor biológico deste e a analise produtiva, conforme afirma Sohail et al. (2003). No caso da farinha do resíduo de tucumã, por ser oriundo da extração da polpa, deve-se considerar também os rendimentos e características de extrato utilizável do produto, como afirma Bora (2001), que analisando caracterização polpa de tucumã verificou a importância da caracterização físico-química dos extratos e subprodutos do tucumã para sua utilização em diversos segmentos da indústria.

Com o aumento dos níveis de F.R.T. nas rações, verifica-se uma aproximação maior do ponto de equilíbrio para o retorno liquido nulo, sendo este resultado devido o aumento do valor agregado bruto proporcionalmente a queda da receita bruta. Então, percebe-se que quanto maior o nível de inclusão de F.R.T. nas rações, menor o volume de produção exigido para se arcar com os custos com alimentação.

Alimentos alternativos em rações tendem a alterar o custo total de produção, principalmente os alimentos que possuem potencial real de substituição de milho ou farelo de soja, insumos que representam a maior fração das rações, como afirmam Souza et al. (2011) e Carrijo et al. (2010).

A partir dos resultados encontrados, concluiu-se que a farinha do resíduo de tucumã pode ser utilizada como 
Rev. Bras. Saúde Prod. Anim., Salvador, v.16, n.1, p.1-9 jan./mar., 2015 http://www.rbspa.ufba.br ISSN 15199940

ingrediente alternativo nas rações de poedeiras comerciais leves tendo o nível de inclusão de 5\% apresentado maior rentabilidade. Até $20 \%$ de inclusão o custo das rações foi menor e o valor agregado bruto maior.

\section{REFERÊNCIAS}

BORA, P.S.; NARIAN, N.; ROCHA, R.V.M.; DE OLIVEIRA MONTEIRO, A.C.; DE AZEVEDO MOREIRA, R. Characterisation of the oil and protein fractions os Tucuma (Astrocarym vulgare Mart.) fruit pulp and seed kernel. Ciência e Tecnologia de Alimentos, v.3, n.2, p.111-116, 2001.

CARRIJO, A.S.; FASCINA, V.B.; SOUZA, K.M.R. de; RIBEIRO, S. da S.; ALLAMAN, I.B; GARCIA, A. M.L.; HIGA, J.A. Níveis de farelo da raiz integral de mandioca em dietas para fêmeas de frangos caipiras. Revista Brasileira de Saúde e Produção Animal [online], v.11, n.1, p.131-139, 2010.

CLEMENT, C.R.; LLERAS, P.E.; VAN LEEUWEN, J. O potencial das palmeiras tropicais do Brasil: acertos e fracassos das últimas décadas. Revista Brasileira de Agrociência, v.9, n.1/2, p.67-71, 2005.

COSTA, F.G.P.; GOULART, C.C.; COSTA, J.S.; SOUZA, C.J.; BARROS, L.R.; SILVA, J.H.V. Desempenho, qualidade de ovos e análise econômica da produção de poedeiras semipesadas alimentadas com diferentes níveis de raspa de mandioca. Acta Scientiarum. Animal Sciences, v.31, n.1, p.13-18, 2009.
CRUZ, F.G.G.; PEREIRA FILHO, M.; CHAVES, F.A.L. Efeito da substituição do milho pela farinha de apara de mandioca em rações poedeiras comerciais. Revista Brasileira de Zootecnia, v.35, n.6, p.2303-2308, 2006.

FERREIRA, E.S.; LUCIEN, V.G.; AMARAL, A.S.; SILVEIRA, C.S. Caracterização físico-química do fruto e do óleo extraído de tucumã (Astrocaryum vulgare Mart.).

Alimentos e Nutrição, v.19, n.4, p.427433, 2008.

FRANZOI, E.E.; SIEWERDT, F.; RUTZ, F.; BRUN, P.A.R.; GOMES, P.C. Desempenho de frangos de corte alimentados com diferentes níveis de farelo de canola. Ciência Rural, v.28, n.4, p.683-689, 1998.

GRANJA PLANALTO. Manual de manejo das poedeiras Dekalb White. Uberlândia: UFU, 2009. 39p.

LOUREIRO, R.R.S.; RABELLO, C.B.V.; LUDKE, JÚNIOR, W.M.D.; GUIMARÃES, A.A.S.; SILVA, J.H.V. Farelo de tomate (Lycopersicum esculentum Mill.) na alimentação de poedeiras comerciais. Acta

Scientiarum. Animal Sciences, v.29, n.4, p.387-394, 2007.

MILLER, W.P.M.; CRUZ, F.G.G.; CHAGAS, E.O.; SILVA, A.F.; ASSANTE, R.T. Farinha do resíduo de tucumã (Astrocaryum vulgare Mart.) na alimentação de poedeiras. Revista Acadêmica de Ciências Agrárias e Ambientais, v.11, n.1, p.105-114, 2013.

OLIVEIRA, P.B. MURAKAMI, A.E.; GARCIA, E.R.M.; MACARI, M.; SCAPINELLO, C. Influência de fatores antinutricionais da leucena (Leucaena leucocephala e Leucaena cunningan) e 
Rev. Bras. Saúde Prod. Anim., Salvador, v.16, n.1, p.1-9 jan./mar., 2015 http://www.rbspa.ufba.br

do Feijão guandu (Cajanus cajan) sobre o epitélio intestinal e o desempenho de frangos de corte. Revista Brasileira de Zootecnia, v.29, n.6, p.1759-1769, 2000 .

ROSSETTI, J.P. Introdução à economia. São Paulo: Atlas, 1990.

ROSSETTI, J. P. Introdução à economia. 4.ed. São Paulo: Atlas, 2004.

ROSTAGNO, H.S; ALBINO, L.F.T.; DONZELE, J.L.; GOMES, P.C.; OLIVEIRA, R.F. de; LOPES, D.C.; FERREIRA, A.S.; BARRETO, S.L. de $T$. Tabelas brasileiras para aves $\mathrm{e}$ suínos: composição de alimentos e exigências nutricionais. Viçosa:

Universidade Federal de Viçosa, 2011. $252 p$.

SANTOS, J.F.; GRANGEIRO, J.I.T. Desempenho de aves caipiras de corte alimentadas com mandioca e palma forrageira enriquecidas com levedura. Tecnologia \& Ciência Agropecuária, v.6, n.2, p.49-54, 2012.

SILVA, E.P.; RABELLO, C.B.V.; JÚNIOR, W.M.D.; LOUREIRO, R.R.S.; GUIMARÃES, A.A.S.; LIMA, M.B.; ARRUDA, E.M.F.; BARBOSALIMA, R. Análise econômica da inclusão dos resíduos de goiaba e tomate na ração de poedeiras comerciais. Revista Brasileira de Saúde e Produção Animal [online], v.10, n.4, p.774-785, 2009.

SOHAIL, S.S.; BRYANT, M.M.; ROLAND, S.D.A. Influence of dietary fat on economic returns of commercial Leghorns. Journal Applied Poultry Research, v.12, n.3, p.356-361, 2003.
SOUZA, K.M.R.; CARRIJO, A.S.A.; KIEFER, C.B.; FASCINA, V.B.C.; FALCO, A.L.D.; MANVAILER, G.V.E.; GARCÍA, A.M.L. Farelo da raiz integral de mandioca em dietas de frangos de corte tipo caipira. Archivos de Zootecnia, v.60, n.231, p.489-499, 2011.

STATISTICAL ANALYSIS SYSTEM. SAS/STAT Software. Version 9.2. Cary: SAS Institute Inc., 2008.

SUPERCRAC. Ração de custo mínimo. Versão 1.02 para Windows. [S.I]: TD Software, 2004.

Data de recebimento: $15 / 04 / 2014$

Data de aprovação: 16/03/2015 